\title{
On the spectrum of gallium
}

\section{Lecoq De Boisbaudran}

To cite this article: Lecoq De Boisbaudran (1876) On the spectrum of gallium, Philosophical Magazine Series 5, 1:2, 176-176, DOI: 10.1080/14786447608639022

To link to this article: http://dx.doi.org/10.1080/14786447608639022

$$
\text { 册 Published online: } 13 \text { May } 2009 .
$$

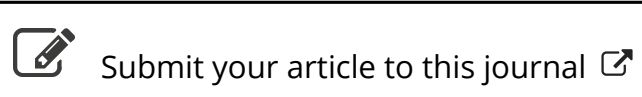

\footnotetext{
Џll Article views: 2
}

Q View related articles $\sqsubset$ 
blendes ; I hope it will not be long ere I possess more ample information on this point.

The gallium which I extracted from the blendes came really from those minerals, and not from the metallic rinc (Vieille-Montagne) employed for the precipitations; for I have obtained no traces of gallium with quantities of this zinc greater than what would have been necessary of blende to get a very pure spectral reaction of gallium.

My last investigations have confirmed the scarcity of gallium in blende. The extreme delicacy of the spectral reaction had even cansed me to estimate too high the quantities obtained. I do not think I exaggerate in saying that, at the time of my first observation, I possessed at most $\frac{\gamma}{100}$ of a milligramme of the new substance dissolved in a very little drop of liquid. I may remark that spectral examination of so minute a quantity would have been impossible before the considerable reduction which I made in the dimensions of the apparatus for obtaining electrical spectra, and without the employment (which I adopted) of very small sparks.

If, as I suppose, there is no error concerning the nature of $\mathrm{my}$ gallium-alum, the existence of this salt fixes the atomicity of the new element, and assigns to its oxide the same chemical function as that of alumina. The oxide of gallium will therefore be written $\mathrm{Ga}_{2} \mathrm{O}_{3}$.-Comptes Rendus de l'Académie des Sciences, Dec. 6, 1875, pp. 1100-1104.

ON THE SPECTRUM OF GALLIUM. BY LECOQ DE BOISBAUDRAN.

I have again measured the wave-lengths of the lines of gallium under conditions of accuracy which the feeble brightness of the spectrum obtained did not permit me to realize at the time of $\mathrm{my}$ first determination*; and I have found precisely the same number for the principal line, while the less brilliant one is a little less refrangible than I at first estimated it.

With the chloride of gallium, considerably more concentrated $\uparrow$, which I have recently submitted to the action of the electric spark, I have observed no other lines than the two following; if, then, others should be found with highly concentrated solutions, they can only be faint.

Position on micrometer.

$\propto 193.72$

$$
\beta 208 \cdot 90 \pm
$$

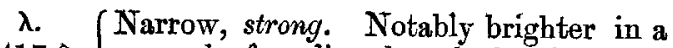
$417 \cdot 0\left\{\begin{array}{l}\text { spark of medium length than in a very } \\ \text { short spark. }\end{array}\right.$

Narrow, well marked, but much fainter

$\beta 20890 \pm$
than a 193.72. Notably brighter with a medium spark than with a very short
one.

The line $\alpha 417.0$ is characteristic of gallium; this is a very delicate

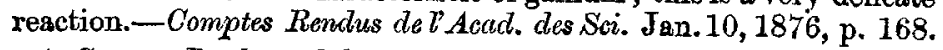

* Comptes Rendus, vol. lxxxvi. p. 494, Sept. 20, 1875; Phil. Mag. [IV.] vol. 1. p. 415.

$\dagger$ The relative intensities indicated in the description of the lines refer to the mean state of concentration of the solution now employed.

$\ddagger$ The line $\mathrm{Ga} \beta$ is much more difficult to measure than $\mathrm{Ga} \infty ; \mathrm{I}$ nevertheless do not think that the error of $\lambda$ much exceeds $0 \cdot 1$. 